\title{
Clinical experience and benefits of buprenorphine treatment in Clinical Center of Montenegro
}

\author{
Author: I. Ljutica MD, Coauthors: Z. Barac Otasevic MD, S. Kalac MD
}

Buprenorphine is an opioid partial agonist. It is a safe and an effective option for the treatment of opioid addiction when is taken as prescribed. Buprenorphine can help to lower the potential for misuse, diminish the effects of physical dependency to opioids, such as withdrawal symptoms and cravings, increase safety in cases of overdose.

Buprenorphine may be abused. Its abuse potential, however, is lower in comparison with that of opioid full agonists.

Benefits of buprenorphine treatment: Suppress symptoms of opioid withdrawal. May reduce illicit opioid use. Help patients stay in treatment. Health problems are reduced or avoided, especially those related to injecting, such as HIV, hepatitis B and hepatitis $C$ viruses, skin infections and vein problems. Doses are required only once a day.

Side effects of buprenorphine: Nausea, vomiting, constipation, muscle aches and cramps, cravings, inability to sleep, distress and irritability, fever, etc.

\section{Pregnant or breastfeeding woman and Buprenorphine:}

There are limited information exists on the use of buprenorphine in women who are pregnant.

\section{Buprenorphine treatment happens in three phases:}

The Induction Phase is the medically monitored startup of buprenorphine treatment. The medication is administered when a person with an opioid dependency has abstained from using opioids for 12 to 24 hours and is in the early stages of opioid withdrawal. It is important to note that buprenorphine can bring on acute withdrawal for patents who are not in the early stages of withdrawal and who have other opioids in their bloodstream.

The Stabilization Phase begins after a patient has discontinued or greatly reduced their misuse of the problem drug, no longer has cravings, and experiences few, if any, side effects. The buprenorphine dose may need to be adjusted during this phase.

The Maintenance Phase occurs when a patient is doing well on a steady dose of buprenorphine. The length of time of the maintenance phase is tailored to each patient and could be indefinite.

\section{Results and Conclusions:}

We followed patients who were included in the buprenorphine substitution treatment for a period of 12 months, to be more precise in the period from January 2018 to December 2018. In January, 148 patients were examined through our Center, while 203 patients were examined in December 2018. From the beginning of the study, we suggested to our patients to do a screening test for Hepatitis $C$ virus. During the study, the number of patients was changing. We have included a lot of, while some users have left treatment. We followed the change in dose as well.

Significant number of patients entered for HCV treatment. For most adults with opioid use disorder, maintenance therapy with buprenorphine is effective treatment approach.

Treatment of opioid dependency with buprenorphine is most effective in combination with counseling services, which can include different forms of behavioral therapy and self-help programs. It can provide a whole-patient approach to the treatment of opioid dependency.

\begin{tabular}{|c|c|c|c|c|c|c|c|c|c|c|c|c|c|c|c|}
\hline Month & Total \# of patients & $2 \mathrm{mg}$ & $4 \mathrm{mg}$ & $6 \mathrm{mg}$ & $8 \mathrm{mg}$ & $10 \mathrm{mg}$ & $12 \mathrm{mg}$ & $14 \mathrm{mg}$ & $16 \mathrm{mg}$ & $18 \mathrm{mg}$ & $20 \mathrm{mg}$ & $22 \mathrm{mg}$ & $24 \mathrm{mg}$ & $26 \mathrm{mg}$ & $28 \mathrm{mg}$ \\
\hline January & 148 & 0 & 1 & 4 & 12 & 8 & 18 & 8 & 45 & 13 & 13 & 3 & 19 & 1 & 1 \\
\hline February & 202 & 0 & 1 & 1 & 21 & 14 & 28 & 15 & 58 & 13 & 21 & 6 & 22 & 2 & 0 \\
\hline March & 175 & 0 & 0 & 2 & 13 & 16 & 20 & 11 & 50 & 13 & 21 & 7 & 4 & 0 & 0 \\
\hline April & 157 & 0 & 0 & 1 & 11 & 11 & 14 & 15 & 15 & 12 & 21 & 6 & 13 & 1 & 0 \\
\hline May & 195 & 0 & 1 & 1 & 11 & 17 & 17 & 18 & 60 & 17 & 26 & 12 & 14 & 1 & 0 \\
\hline June & 182 & 0 & 0 & 0 & 20 & 11 & 13 & 16 & 52 & 17 & 21 & 10 & 18 & 0 & 0 \\
\hline July & 168 & 0 & 0 & 3 & 11 & 11 & 18 & 18 & 61 & 13 & 32 & 9 & 14 & 0 & 0 \\
\hline August & 183 & 1 & 1 & 3 & 15 & 9 & 14 & 16 & 66 & 13 & 26 & 13 & 12 & 0 & 0 \\
\hline September & 204 & 0 & 1 & 4 & 8 & 13 & 16 & 20 & 72 & 19 & 24 & 19 & 8 & 0 & 0 \\
\hline October & 200 & 0 & 1 & 4 & 5 & 12 & 17 & 21 & 76 & 23 & 18 & 19 & 4 & 0 & 0 \\
\hline November & 206 & 0 & 1 & 3 & 10 & 12 & 13 & 24 & 81 & 22 & 22 & 12 & 6 & 0 & 0 \\
\hline December & 203 & 0 & 3 & 4 & 8 & 13 & 17 & 20 & 80 & 20 & 22 & 10 & 6 & 0 & 0 \\
\hline
\end{tabular}

\section{Total \# of patients}

$24 \%$

$25 \%$
$\mathrm{HCV}+$

\section{$51 \%$}

$\mathrm{HCV}$

Refused to be tested 